See discussions, stats, and author profiles for this publication at: https://www.researchgate.net/publication/263118491

\title{
Spatial and temporal dynamics of Sorghum halepense patches in maize crops
}

Article in Weed Research · October 2012

DOI: $10.1111 / j .1365-3180.2012 .00937 . x$

\section{CITATIONS}

20

4 authors:

Dionisio Andújar

Spanish National Research Council

104 PUBLICATIONS 996 CITATIONS

SEE PROFILE

Cesar Fernandez-Quintanilla

Spanish National Research Council

201 PUBLICATIONS 2,394 CITATIONS

SEE PROFILE
93

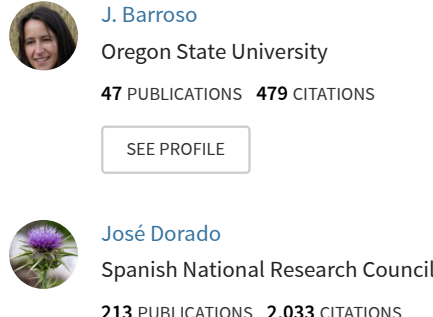

213 PUBLICATIONS 2,033 CITATIONS

SEE PROFILE

Some of the authors of this publication are also working on these related projects:

Robot fleets for highly effective crop management in Mediterranean agriculture (RHEA) View project

Impacts of mixed cereal-oilseed cropping systems on weed communities in the PNW View project 
Spatial and temporal dynamics of Sorghum halepense patches in maize crops

D ANDÚJAR, J BARROSO, C FERNÁNDEZ-QUINTANILLA \& J DORADO

Instituto de Ciencias Agrarias, CSIC, Serrano 115 B, 28006 Madrid, Spain

Author for correspondence: JOSÉ DORADO

Address: Instituto de Ciencias Agrarias, CSIC, Serrano 115 B, 28006 Madrid, Spain

Telephone number: +34917452500

E-mail address: jose.dorado@ica.csic.es

Short title: Spatial and temporal dynamics of Sorghum halepense patches

Total word count: 5884 words 


\section{Summary}

Patches of Sorghum halepense of various sizes and densities were artificially created in a maize field. Spatial and temporal patch expansion was monitored during four years. The results show that patches expanded in the same direction of field traffic, with little or no displacement in all the other directions. Apparently, tillage was the main mechanism for dispersal of $S$. halepense rhizomes with seeds playing a minor role in dispersal. The spatial growth pattern was characterized by a compact spread of the original patch and by the appearance of small patches at various distances from the primary source, which tended to merge with each other and with the original source. This type of pattern indicates an 'infiltration' invasion strategy. The initial patch size significantly influenced their growth rate: small patches grew proportionately faster than larger patches. The initial plant density had a significant influence on the temporal dynamics: low density patches increased up to 130 shoots $\mathrm{m}^{-2}$, the same upper level reached by high density patches. Sorghum halepense seems to be an excellent target for Site-Specific Weed Management (SSWM), with compact patches expanding slowly and in a highly predictable way. However, new foci detached from the original source can expand quickly and could invade the whole field in a relatively short time. An early detection and management of small patches can contribute to improve SSWM practices.

Key-words: Weed patch dynamics; site-specific weed management; perennial weeds. 


\section{Introduction}

Weed populations are irregularly distributed within crop fields. Weed patches vary greatly from field to field, with variable sizes, shapes and densities (Cardina et al., 1997; Dieleman \& Mortensen, 1999). Climatic and cropping variation may cause patches to be more evident in some years than in others, making the patches to 'wax and wane' (Nordmeyer, 2009). Although patch edges may vary highly from year to year, the central areas of the patches are more stable spatially (Mortensen \& Dieleman, 1998). In general, aggregation and patch stability is higher in perennial species than in annuals due to dispersal is limited to short distances by their vegetative reproduction. Annuals, in contrast, are distributed more randomly due to their capacity for seed dispersal, which provides greater ability to colonize weed-free areas.

In spite of the fact that the aggregated distribution of weeds is the base of site-specific weed management (SSWM), there is little information published on patch expansion and distribution, particularly with perennial weeds. Various studies have shown that Cirsium arvense patches were more stable than those of various annual weeds (Colbach et al., 2000; Hamouz et al., 2004). However, little specific information is available for other perennial weeds (Webster et al., 2000; Guglielmini \& Satorre, 2003; Jurado-Exposito et al., 2004). This information is essential for understanding their spatial dynamics, which is necessary for planning and conducting SSWM.

Sorghum halepense (L.) Pers. is an extremely widespread species. It is considered one of the most troublesome weeds on the world (Holm et al., 1977) and it is a common weed in maize in various regions of Spain (Andújar et al., 2011). Numerous studies have shown that the interference of S. halepense with maize can greatly reduce crop yields (Bendixen, 1986; Mueller et al., 1993; Ghosheh et al., 1996; Vasilakoglou et al., 2005) 
The ability of $S$. halepense to colonize new areas, its establishment and its persistence depend on many factors. Combine harvesters have been reported to increase significantly dispersal distances of this species (Ghersa et al., 1993; Barroso et al., 2012). However, the actual role of seeds in population growth is still not clear. Seed predation has been found to contribute largely to population control (Scopel et al., 1988). In seed-propagated plants, the new seedlings are subjected to many mortality factors: pre-planting tillage, pre-emergence and post-emergence herbicides, and inter-row cultivation. In contrast, plants coming from rhizomes are, apparently, much less affected by all these factors. Soil tillage spreads rhizomes and favors $S$. halepense to colonize new areas. In the absence of tillage, this weed spreads as a circular-shaped patch with no preferential direction of growth (Horowitz, 1973). However, a survey conducted in commercial maize fields in Spain (all of them under conventional tillage) showed a differential growth of patches according to tillage direction, with patches being twice as long in the direction of tillage (Andújar et al., 2011).

The objective of this study was to characterize the growth of $S$. halepense patches in a continuous maize field over four growing seasons, analyzing the influence of initial patch size and plant density on the spatial and temporal patch expansion and anisotropy. Knowledge of the dynamics of $S$. halepense patches growing under field conditions is essential to planning effective prevention and control measures in the context of SSWM.

\section{Materials and methods}

\section{Site Location and Description}

Field experiments were conducted from 2007 to 2010 at La Poveda Research Farm (Arganda del Rey, Madrid, Central Spain), in a 2 ha maize field that was free from S. halepense and with low infestation of other weeds. The landscape of the site is an alluvial plain in the Jarama 
river basin with a flat topography. Soil has a sandy-loam texture with $39 \%$ sand, $47 \%$ silt, $14 \%$ clay, and $1.4 \%$ organic matter, $\mathrm{N} 0.75 \mathrm{~g} \mathrm{~kg}^{-1}, \mathrm{CaCO}_{3} 34 \mathrm{~g} \mathrm{~kg}^{-1}$ and $\mathrm{pH} 8.1$.

Maize was planted all four years in mid April with 75-cm row spacing with a population of 80,000 plants ha ${ }^{-1}$. Fertilizers were applied at planting time $(40 \mathrm{~kg} \mathrm{~N}, 75 \mathrm{~kg}$ P and $75 \mathrm{~kg} \mathrm{~K}$ $\left.\mathrm{ha}^{-1}\right)$ and at the eight-leaf stage $\left(100 \mathrm{~kg} \mathrm{~N} \mathrm{ha}^{-1}\right)$. Pre-emergence herbicide treatment with Smetolachlor + terbutilazine $\left(0.94+0.56 \mathrm{~kg}\right.$ ai ha $\left.{ }^{-1}\right)$ was applied in 2007 , with isoxaflutol $\left(0.07 \mathrm{~kg}\right.$ ai ha $\left.{ }^{-1}\right)$ in 2008 , and with S-metolachlor + mesotrione $\left(1.20+0.12 \mathrm{~kg}\right.$ ai ha $\left.{ }^{-1}\right)$ in 2009 and 2010. No specific herbicides were applied in post-emergence (e.g., nicosulfuron) to control S. halepense in any case. All the agricultural operations (ploughing, seed drilling, spraying and combine harvesting) were conducted parallel to the longest side of the fields and always in the same direction, in order to assess the effect of traffic direction in the pattern of expansion of S. halepense patches. The tillage system used included disking the maize stubble after harvesting, moldboard ploughing during the winter and preplanting tillage with a field cultivator. Sprinkler irrigation was used, providing ample water for crop and weed growth.

\section{Experimental Design}

Three separated experiments were established in order to assess the potential of expansion of S. halepense as a function of initial patch size and plant density.

In the first two experiments, patches of $S$. halepense were created by transplanting rhizomes collected during the previous winter from a highly infested area in a nearby field. Rhizomes remained buried near the experimental plot until the start of the experiment. Then, rhizomes were prepared for planting by removing the secondary roots and cutting into 2-node pieces to reproduce the fragmentation effect caused by soil tillage and seedbed preparation. Rhizomes pieces containing two buds each were transplanted on $27^{\text {th }}$ March 2007, previously to maize sowing. Both experimental designs were randomized complete block design with 
three replications. The first experiment, evaluating the effect of the initial patch size, consisted of patches artificially established with the same weed density $\left(10\right.$ shoots $\left.\mathrm{m}^{-2}\right)$ but different patch sizes: $1 \mathrm{~m}^{2}, 10 \mathrm{~m}^{2}$ and $100 \mathrm{~m}^{2}$. The second experiment evaluated the effect of initial S. halepense density. In this case, the initial patch size was always $10 \mathrm{~m}^{2}(3.3 \mathrm{~m} \times 3.3$ m) and established densities were 4, 20 and 100 shoots $\mathrm{m}^{-2}$. Each plot was established in a 25 $\mathrm{m} \times 65 \mathrm{~m} \mathrm{~S}$. halepense-free area in order to assess weed spread in the following three seasons without interfering with other plots. Plots were established at $1 / 3$ of distance from the beginning of its allotted area in the direction of field traffic and in the centre of the field portion in the perpendicular direction (Fig. 1). Initial planting was made by evenly distributing the rhizomes onto the soil surface of the required patches. Shoot emergence was assessed 4 weeks after planting and unsprouted rhizomes were re-planted in order to achieve the established density for each treatment.

A third experiment was conducted in order to evaluate the capability of individual $S$. halepense plants to create and establish permanent patches. Seven rhizome pieces containing two buds each were transplanted on $27^{\text {th }}$ March 2007 in a nearby $12 \mathrm{~m} \times 56 \mathrm{~m}$ strip free of $S$. halepense (Fig. 2). Rhizome pieces were transplanted $8 \mathrm{~m}$ from each other along a straight line in the same direction than traffic operations.

\section{Patch Monitoring}

In order to assess the expansion of $S$. halepense patches by agricultural operations (primary and secondary tillage, planting, harvesting) and by natural dissemination, patches of the first two experiments were georreferenced during four growing seasons in the maize stage $\mathrm{BBCH}$ 16-18, when most of $S$. halepense vegetative shoots were emerged. The perimeter of the patches was defined using a geopositioning system receiver with Omnistar differential correction (DGPS) working in a frequency of $5 \mathrm{~Hz}$. An operator walked around the patch 
perimeter, registering points along the patch border. In order to determine population changes in weed density within patches, shoots of $S$. halepense present in every inter-row area were sampled, using a $0.66 \mathrm{~m} \times 0.33 \mathrm{~m}$ quadrat that was located at each meter within each row.

Furthermore, in the third experiment evaluating spatial and temporal dynamics of individual S. halepense plants, all individual shoots were manually counted and each one was geo-referenced with DGPS coordinates during 2007 and 2008 seasons. Due to the high patch growth in 2009 and 2010 it was not possible to monitor each individual shoot. Therefore, the perimeter of the patches was assessed using a DGPS system as described previously. Spatial data for shoot emergence of $S$. halepense was analyzed over the time, and S. halepense maps were created in order to describe the spatial and temporal expansion patterns.

\section{Data Analyses}

The geopositioning data were managed using ArcMap ${ }^{\circledR} 10.1$, creating polygon maps by merging points, integrating the area, perimeter, maximum length in the traffic direction, maximum width perpendicular to traffic direction, and centroids for each patch during the four years. Differences in weed density between treatments were analyzed by the KruskallWallis test.

In order to describe the spatio-temporal evolution of patches, various parameters were assessed. Total patch area was the major descriptor used to assess the expansion of patches into the space. The complexity index (ratio area perimeter $^{-2}$ ) was used as an estimator of regularity of patch shape (Ruiz et al., 2006; Andújar et al., 2011). The lower the ratio the more complex and irregular was the patch. Patch anisotropy was studied by comparing the projection in the direction of traffic and the projection in the direction perpendicular to traffic. The changes of distance and direction of the patch centroids from one year to the next were calculated following the procedures described by Krohmann et al. (2006). The expansion to 
weed free areas was studied by assessing the new foci of $S$. halepense, using the previous parameters as well as the distance and angle to their patch of origin.

\section{Results}

\section{Patch Size Growth}

During the four experimental years, patches expanded gradually into the nearby space. Patch growth was observed almost exclusively in the traffic direction with small displacements in the two perpendicular directions or backward (Fig. 1). In addition, new foci of infestation separated from original patches were found in the direction of traffic.

Initial patch size was the factor with the largest influence in the relative patch growth (Table 1). Patches of $1 \mathrm{~m}^{2}$ increased their size more than 17 times during the first year and 137 times at the end of the four year period. Medium size patches $\left(10 \mathrm{~m}^{2}\right)$ grew at a slower rate, expanding their initial area 22 times during the four years. The largest patches $\left(100 \mathrm{~m}^{2}\right)$ increased their sizes 5 times during the four year period. Apparently, the rate of expansion slowed with the time and patch size: small patches tended to expand rapidly initially but once they reached medium or large sizes their relative growth decreased gradually.

The effect of initial plant density on patch size growth was not significant (Table 1). Patches with 4 plants $\mathrm{m}^{-2}$ increased their size 5 times during the first year and 31 times after four years. Medium (20 shoots $\mathrm{m}^{-2}$ ) and high $\left(100\right.$ shoots $\left.\mathrm{m}^{-2}\right)$ density patches showed a similar tendency increasing their size by the fourth year 20 and 42 times, respectively.

\section{Plant Density Growth}

Practically all treatments followed the same trend, with plant density increasing exponentially during the growth period reaching a maximum in the fourth year (Fig. 3). Initial patch size did not have any significant effect on population growth (Fig. 3a). In relation to the initial density 
of plants, the evolution of S. halepense density was somewhat diverse (Fig. 3b). Patches started with 4 and 20 shoots $\mathrm{m}^{-2}$ had very similar densities in the four years, reaching 120 to 130 shoots $\mathrm{m}^{-2}$ on average at the end of the experiment. In contrast, patches started with 100 shoots $\mathrm{m}^{-2}$ showed a decline in density in the second year (down to 25 shoots $\mathrm{m}^{-2}$ ) followed by a recovery in the two other years. At the end of the experimental period, shoot density was similar than in the two other treatments.

\section{Spatial Patterns}

The displacement in distance and direction of the patches was studied by analyzing the movement of the centroids. Centroid displacement was relatively similar in different years and treatments, with values ranging from 1.6 to $8.3 \mathrm{~m}$ per year (Table 2). The changes of direction of the patch centroids were nearly parallel to traffic direction with values ranging between $-23^{\circ}$ and $+25^{\circ}$. Neither the initial patch size nor initial plant density had significant effects on these displacements.

Patch expansion took place following two different patterns: a) spreading uniformly as a compact patch; and b) generating new foci that, in subsequent years, merged with the original patch. In general, large patches generated new foci more often and at greater distances from the origin than small patches (Table 3). In this experiment, no new foci were detected one year after planting (2008). In 2009, the smallest patches (originally $1 \mathrm{~m}^{2}$ ) produced 2 new foci (with an average perimeter of $0.7 \mathrm{~m}$ ) displaced $13 \mathrm{~m}$ from the origin, whereas the largest patches (originally $100 \mathrm{~m}^{2}$ ) produced 7 new foci (with a $12.3 \mathrm{~m}$ average perimeter) displaced $42 \mathrm{~m}$ from the origin. In 2010, the number of new foci decreased, probably due to the fact that patch and foci expansion connected some of the patches/foci. Foci which were not connected with other patches increased their area and perimeter over the time. All the new patches emerged in the traffic direction and none were found outside this 
direction. In addition, the change of direction of the new foci centroids respect to the original patch centroids was almost parallel to traffic direction. On the other hand, similar characteristics in the new foci were observed depending on the initial plant density.

\section{Spatial Indexes}

The complexity index (relationship between area and squared perimeter) provides information about how compact or regular are patches. In general, patches tended to decrease this ratio with time (Fig. 4). This means that patches became less regular when they grew in size and density. This decline in regularity was particularly evident in the first three years of the experiment, regardless of the initial patch size and plant density.

Evolution in patch anisotropy (relationship between the projections parallel to traffic direction and perpendicular to traffic direction) is shown in Fig. 5. In 2007, because of the squares shape of the recently established patches, the length/width ratio was 1 . In the following three years, this ratio increased on average to $2.3,3.2$ and 4.4 times longer than wider in the direction of traffic, respectively. Initial patch size and plant density had no significant influence on the evolution of this index.

\section{Individual Plant Expansion}

Although seven plants were established in 2007, only six survived in the following year. The high capacity of these plants to colonize weed free areas is shown in Fig. 2. Patch growth during the initial year (without additional tillage after planting) followed a circular pattern, with no preferential direction of growth for new vegetative shoots (data not shown). The year after planting, the original plants formed small patches with some shoots emerging at distances higher than $3 \mathrm{~m}$ from the origin. This expansion continued during 2009, with some patches reaching up to $20 \mathrm{~m}^{2}$. These larger patches were formed either by the expansion of 
smaller patches either by merging two or more patches. In 2010 a single patch $70 \mathrm{~m}$ long and $4 \mathrm{~m}$ wide, covering an area of $237 \mathrm{~m}^{2}$, occupied practically all the experimental area. Thus, soil tillage resulted in clear patch anisotropy.

A progressive increase in the number of shoots emerged from these individual plants was observed during the first two years (Fig. 6). At the end of the second growing season, the density of S. halepense increased up to 22 shoots $\mathrm{m}^{-2}$ from each individual plant established the first year.

\section{Discussion}

Based on the results of this study we can establish some important features of S. halepense patch dynamics in a continuous maize cropping. The data collected for 4 years using the contour maps of the patches provided precise spatial information, avoiding spatial interpolation techniques. According with these data, the size of S. halepense patches increased annually 2 to 17 times depending on patch size. Although the relative growth of patches was larger in the smaller patches, the actual patch displacement (measured by the displacement of their centroids) was relatively similar for all patch sizes. Obviously, a displacement of $4 \mathrm{~m}$ in a $1 \mathrm{~m}^{2}$ patch represents a much larger proportional expansion than the same displacement in a $100 \mathrm{~m}^{2}$ patch. It is likely that due to the faster expansion of small patches, the relative differences in size will be reduced over time compared to large patches. Thus, small patches may become large patches and then expand more slowly, but this needs confirmation in a long-term study. According to a survey of maize fields infested by this weed, most of the area was concentrated in a few large patches: only $5 \%$ of the infested area corresponded to patches smaller than $50 \mathrm{~m}^{-2}$ (Andújar et al., 2011).

Previous studies had shown that S. halepense expands without preferential direction, establishing patches with approximately circular shape (Horowitz, 1973). However, these 
results were obtained with plants grown without any soil tillage. In our study, the use of a unique direction for all agricultural operations (including tillage) created a clear spatial pattern with elongated patches in the direction of field traffic and little or no movement in all the other directions. This effect was clearly observed by the small changes of direction of the patch centroids, the evolution of the complexity index and the anisotropy of the patches. These results indicate that tillage is the main mechanism for spatial dispersal of S. halepense as was confirmed by the results of the individual plant experiment.

In this study, although the results of the first year were coincident with those of Horowitz (1973), once tillage was started (in the second year after planting), the patches expanded in an anisotropic pattern. Throughout the experimental period, the spatial distribution pattern became increasingly complex with the appearance of new foci. This growth pattern is, apparently, in accordance with the dual strategy of population growth proposed by Lovett Doust (1981). While the main patches tended to grow according to a 'phalanx' strategy, spreading compact from a central point of establishment, new infestation foci showed a 'guerrilla' strategy, exhibiting directional dispersal and proliferating far away from the original patches along one or a few axes. Both, compact spread around the primary source and occasional hopes to new sites occurred at the same time, with new foci merging among them and with the original source. Due to the fact that growth of small patches is proportionally much faster than spread of the primary source, both processes may contribute to field invasion. This type of growth resembles more the 'infiltration' pattern proposed by Wilson \& Lee (1989). This pattern is probably associated to the existence of two different dispersal mechanisms: short-distance by vegetative growth and medium or long distance by tillage operations. One consequence of this result is that patch spread can be minimized by using notillage systems. 
Although Ghersa et al. (1993) attributed the spread of S. halepense to both rhizomes and seeds our results suggest that $S$. halepense relies predominantly on vegetative dispersal, with a negligible effect of seed dispersal. Sorghum halepense plants observed during the visual assessments of the patches and during population sampling on quadrats were, apparently, vigorous shoots coming from rhizomes. Some small seedlings were detected later in the center of the patches, but they were relatively easy to distinguish from the rhizome shoots. Furthermore, studies conducted to assess the influence of combine harvesting maize on seed dispersal of this weed have shown that seeds can be dispersed forward long distances and backward up to $12 \mathrm{~m}$ from the infestation source (Barroso et al., 2012). However, our results show both, that annual patch displacement is relatively small and that the movement of the patches in the backward direction is almost nil. One possible explanation of the small role of seeds in patch displacement would be seed predation (Scopel et al., 1988). However, in our experiment we did not detect any symptoms of seed predation by insects and/or rodents. We attribute the low relevance of seeds in $S$. halepense patch spread to a low seedling survivorship. Although we observed numerous seedlings in early stages of maize crop, most of them were not able to complete their life cycle, probably due to the effect of pre-emergence herbicides and to crop and weed competition. S-metolachlor, one of the pre-emergence herbicides used in the experimental field, is effective in controlling S. halepense seedlings before they emerge. Other studies have shown that $S$. halepense vegetative shoots are harder to control and more competitive than young seedlings (Millhollon, 1993; Rosales-Robles et al., 1999a; Mitskas \& Eleftherohorinos 2003).

The population dynamics of low density patches $\left(\leq 20\right.$ shoots $\left.\mathrm{m}^{-2}\right)$ was characterized by an exponential growth, reaching densities up to 130 shoots $\mathrm{m}^{-2}$ in a 4-year period. In contrast, in patches with high plant density $\left(100\right.$ shoots $\left.\mathrm{m}^{-2}\right)$ we observed an initial population decrease followed by a recovery to levels close to the other treatments. Apparently, S. halepense in 
maize fields has a carrying capacity close to 130 shoots $\mathrm{m}^{-2}$. Athough Horowitz (1973) reported that one single plant produced 100 shoots $\mathrm{m}^{-2}$ in the first year and up to 165 shoots $\mathrm{m}^{-2}$ after two years, that study was conducted in the absence of crop competition. Maize competes strongly with S. halepense and limits its potential density. Population densities recorded in other studies conducted in maize fields heavily infested by this weed show population densities ranging from 40 to 60 shoots $\mathrm{m}^{-2}$ (Eleftherohorinos \& Kotoula-Syka, 1995; Rosales-Robles et al., 1999b).

The results obtained in this study have several important implications for SSWM of $S$. halepense. Previous studies have shown that the economic feasibility of using SSWM systems is conditioned by the frequency of re-mapping (Barroso et al., 2004; Van Wychen et al., 2002). Our results indicate that $S$. halepense patches are generally very compact and they expand slowly in a highly predictable way (in the same direction of field traffic). Consequently, a map obtained at a given time could be used in the decision making process later in the same season or in the following season. The information provided by our study can be used in spatial models designed to predict patch location at different time periods. This would be very desirable in terms of improving the feasibility of SSWM systems for this weed. Nevertheless, due to the fact that new foci can expand rapidly, new small patches are a potential hazard if they are not managed adequately. Therefore, it is required to devise action plans to account with this fact. One possible option is to reduce as much as possible weed detection and herbicide application resolution in order to spray not only the large patches but also the small foci. This 'small pixel' option will also provide the potential to lower the total amount of herbicide used (Wallinga et al., 1998). However, this improved control and higher herbicide savings has to be balanced by the extra engineering costs. Another option is to spray the standard rate of herbicides to the large compact patches and apply reduced rates of the same products to the remaining field area. This 'variable rate' option would probably result in 
higher amounts of herbicides used. Furthermore, some recent research suggests that low herbicide rates may promote herbicide resistance (Manalil et al., 2011).

\section{Acknowledgements}

This research was funded by the Spanish CICyT (project AGL 2008-04670-C03).

\section{References}

ANDÚJAR D, RUIZ D, RIBEIRO A, FERNÁNDEZ-QUINTANILLA C \& DORADO J (2011) Spatial distribution patterns of johnsongrass (Sorghum halepense) in corn fields in Spain. Weed Science 59, 82-89.

BARROSO J, ANDÚJAR D, SAN MARTÍN C, FERNÁNDEZ-QUINTANILLA C \& DORADO J (2012) Johnsongrass (Sorghum halepense) seed dispersal in corn crops under Mediterranean conditions. Weed Science 60, 34-41.

BARROSO J, FERNÁNDEZ-QUINTANILLA C, RUIZ D, HERNÁIZ P \& REW LJ (2004) Spatial stability of Avena sterilis ssp. ludoviciana populations under annual applications of low rates of imazamethabenz. Weed Research 44, 178-186.

BENDIXEN LE (1986) Corn (Zea mays) yield in relationship to johnsongrass (Sorghum halepense) population. Weed Science 34, 449-451.

CARDINA J, JOHNSON GA \& SPARROW DH (1997) The nature and consequence of weed spatial distribution. Weed Science 45, 364-373.

COLBACH N, FORCELLA F \& JOHNSON GA (2000) Spatial and temporal stability of weed populations over five years. Weed Science 48, 366-377.

DIELEMAN JA \& MORTENSEN DA (1999) Characterizing the spatial pattern of Abutilon theophrasti seedling patches. Weed Research 39, 455-467. 
ELEFTHEROHORINOS IG \& KOTOULA-SYKA E (1995) Influence of herbicide application rate and timings for post-emergence control of Sorghum halepense (L.) Pers. in maize. Weed Research 35, 99-103.

GHERSA CM, MARTINEZ-GHERSA MA, SATORRE EH, VANESSO ML \& CHICHOTKY G (1993) Seed dispersal, distribution and recruitment of seedlings of Sorghum halepense (L.) Pers. Weed Research 33, 79-88.

GHOSHEH HZ, HOLSHOUSER DL \& CHANDLER JM (1996) Influence of density on johnsongrass (Sorghun halepense) interference in field corn (Zea mays). Weed Science 44, 879-883.

GUGLIELMINI AC \& SATORRE EH (2004) The effect of non-inversion tillage and light availability on dispersal and spatial growth of Cynodon dactylon. Weed Research 44, $366-374$

HAMOUZ P, SOUKUP J, HOLEC J \& JURSIK M (2004) Field-scale variability of weediness on arable land. Plant Soil and Environment 50, 134-140.

HOLM LG, PLUCKNETT DL, PANCHO JV \& HERBERGER JP (1977) The Worlds`s Worst Weeds. Distribution and Biology. University of Hawaii Press, Honolulu, HA.

HOROWITZ M (1973) Spatial growth of Sorghum halepense (L.) Pers. Weed Research 13, $200-208$.

JURADO-EXPÓSITO M, LÓPEZ-GRANADOS F， GONZÁLEZ-ANDÚJAR JL \& GARCÍA-TORRES L (2004) Spatial and temporal analysis of Convolvulus arvensis L. populations over four growing seasons. European Journal of Agronomy 21, 287-296.

KROHMANN P, GERHARDS R \& KUHBAUCH W (2006) Spatial and temporal definition of weed patches using quantitative image analysis. Journal of Agronomy and Crop Science 192, 72-78. 
LOVETT DOUST L (1981). Population dynamics and local specialization in a clonal perennial (Ranunculus repens). I. The dynamics of ramets in contrasting habitats. Journal of Ecology 69, 743-755.

MANALIL S, BUSI R, RENTON M \& POWLES SB (2011) Rapid evolution of herbicide resistance by low herbicide dosages. Weed Science 59, 210-217.

MILLHOLLON RW (1993) Preemergence control of itchgrass (Rottboellia cochinchinensis) and johnsongrass (Sorghum halepense) in sugarcane (Saccharum spp hybrids) with pendimenthalin and prodiamine. Weed Science 41, 621-626.

MITSKAS MB, ELEFTHEROHORINOS IG \& DAMALAS CA (2003) Interference between corn and johnsongrass (Sorghum halepense) from seed or rhizomes. Weed Science 51, $540-545$.

MORTENSEN DA \& DIELEMAN JA (1998) Why weed patches persist: dynamics of edges and density. Precision Weed Management in Crops and Pastures (eds R.W. Medd \& J.E. Pratley), pp. 14-19. CRC for Weed Management Systems, Adelaide, Australia.

MUELLER JP, LEWIS WM, GREEN JT \& BURNS JC (1993) Yield and quality of silage corn as altered by johnsongrass infestation. Agronomy Journal 85, 49-52.

NORDMEYER H (2009) Spatial and temporal dynamics of Apera spica-venti seedling populations. Crop Protection 28, 831-837.

ROSALES-ROBLES E, CHANDLER JM, SENSEMAN SA \& PROSTKO EP (1999a) Influence of growth stage and herbicide rate on postemergence johnsongrass (Sorghum halepense) control. Weed Technology 13, 525-529.

ROSALES-ROBLES E, CHANDLER JM, SENSEMAN SA \& PROSTKO EP (1999b) Integrated johnsongrass (Sorghum halepense) management in field corn (Zea mays) with reduced rates of nicosulfuron and cultivation. Weed Technology 13, 367-373. 
RUIZ D, ESCRIBANO C \& FERNÁNDEZ-QUINTANILLA C (2006) Assessing the opportunity for site-specific management of Avena sterilis in winter barley fields in Spain. Weed Research 46, 379-387.

SCOPEL AL, BALLARE CL \& GHERSA CM (1988) Role of seed reproduction in the population ecology of Sorghum halepense in maize crops. Journal of Applied Ecology 25, 951-962.

VAN WYCHEN LR, LUSCHEI EC, BUSSAN AJ \& MAXWELL BD (2002) Accuracy and cost effectiveness of GPS-assisted wild oat mapping in spring cereal crops. Weed Science 50, $120-129$.

VASILAKOGLOU I, DHIMA K \& ELEFTHEROHORINOS I (2005) Allelopathic potential of bermudagrass and johnsongrass and their interference with cotton and corn. Agronomy Journal 97, 303-313.

WALLINGA J, GROENEVELD RMW \& LOTZ LAO (1998) Measures to describe weed spatial patterns at different levels of resolution and their application for patch spraying weeds. Weed Research 38, 351-359.

WEBSTER TM, CARDINA J \& WOODS SJ (2000) Spatial and temporal expansion patterns of Apocynum cannabinum patches. Weed Science 48, 728-733.

WILSON JB \& LEE WG (1989) Infiltration invasion. Functional Ecology 3, 379-380. 
Table 1. Relative growth of Sorghum halepense patches in different experimental years referred to the year of planting (2007).

\begin{tabular}{|c|c|c|c|c|c|c|}
\hline \multirow[b]{2}{*}{ Factor studied } & \multicolumn{2}{|c|}{$2007 / 2008$} & \multicolumn{2}{|c|}{$2007 / 2009$} & \multicolumn{2}{|c|}{$2007 / 2010$} \\
\hline & Growth & SD* & Growth & SD & Growth & $\mathrm{SD}$ \\
\hline \multicolumn{7}{|l|}{ Initial patch size $\left(\mathrm{m}^{2}\right)$} \\
\hline 1 & 17.3 & 10.5 & 30.0 & 19.3 & 137.3 & 101.6 \\
\hline 10 & 5.7 & 1.1 & 8.6 & 0.9 & 22.3 & 1.5 \\
\hline 100 & 2.3 & 0.4 & 3.5 & 0.8 & 5.4 & 3.7 \\
\hline Significance $(95 \%)$ & 0.05 & & 0.05 & & 0.03 & \\
\hline \multicolumn{7}{|c|}{ Initial plant density (shoots $\mathrm{m}^{-2}$ ) } \\
\hline 4 & 5.3 & 1.0 & 10.3 & 2.2 & 31.1 & 13.7 \\
\hline 20 & 4.9 & 3.7 & 8.7 & 3.4 & 20.1 & 20.1 \\
\hline 100 & 8.3 & 2.5 & 12.0 & 1.1 & 42.6 & 11.8 \\
\hline Significance $(95 \%)$ & 0.15 & & 0.59 & & 0.43 & \\
\hline
\end{tabular}

* Standard deviations of three patches. 
Table 2. Average distance $(\mathrm{m})$ between centroids and change of direction (degrees) of the patch centroids in different experimental years referred to the year of planting (2007). In parentheses is shown the standard deviation for the three patches.

\begin{tabular}{|c|c|c|c|c|c|c|}
\hline \multirow[b]{2}{*}{ Factor studied } & \multicolumn{2}{|c|}{$2007 / 2008$} & \multicolumn{2}{|c|}{$2007 / 2009$} & \multicolumn{2}{|c|}{$2007 / 2010$} \\
\hline & Distance & Shift direction & Distance & Shift direction & Distance & Shift direction \\
\hline \multicolumn{7}{|l|}{ Initial patch size $\left(\mathrm{m}^{2}\right)$} \\
\hline 1 & $2.9(0.9)$ & $-22.4^{\circ}(12.8)$ & $3.0(1.2)$ & $24.8^{\circ}(22.0)$ & $4.9(4.0)$ & $-4.9(42.1)$ \\
\hline 10 & $2.9(2.0)$ & $-15.3^{\circ}(28.5)$ & $1.6(1.3)$ & $9.0^{\circ}(47.8)$ & $7.0(5.1)$ & $-14.9(29.0)$ \\
\hline 100 & $4.1(2.9)$ & $-21.6^{\circ}(24.9)$ & $3.8(4.3)$ & $-1.9^{\circ}(39.4)$ & $8.3(7.2)$ & $-13.7(28.4)$ \\
\hline Significance $(95 \%)$ & ns & ns & $\mathrm{ns}$ & $\mathrm{ns}$ & $\mathrm{ns}$ & ns \\
\hline \multicolumn{7}{|c|}{ Initial plant density (shoots $\mathrm{m}^{-2}$ ) } \\
\hline 4 & $2.7(1.9)$ & $-23.2^{\circ}(24.8)$ & $3.4(2.4)$ & $-8.1^{\circ}(34.5)$ & $4.7(3.9)$ & $-16.2^{\circ}(29.9)$ \\
\hline 20 & $6.1(1.8)$ & $-20.9^{\circ}(15.4)$ & $4.2(3.6)$ & $15.6^{\circ}(18.4)$ & $2.4(-)$ & $12.9^{\circ}(-)$ \\
\hline 100 & $5.9(1.7)$ & $-10.8^{\circ}(6.5)$ & $4.7(2.7)$ & $15.0^{\circ}(4.6)$ & $6.4(-)$ & $4.6^{\circ}(-)$ \\
\hline Significance $(95 \%)$ & ns & ns & $\mathrm{ns}$ & $\mathrm{ns}$ & $\mathrm{ns}$ & ns \\
\hline
\end{tabular}


Table 3. Description of new foci of Sorghum halepense in the three years following planting based on the initial patch size and the initial plant density. The descriptors include the number of new foci, distance to their patch of origin $(\mathrm{m})$, area $\left(\mathrm{m}^{2}\right)$, perimeter $(\mathrm{m})$ and change of direction of the foci centroids to their patch of origin (angle degrees). In parentheses is shown the standard deviation for three patches of origin.

\begin{tabular}{|c|c|c|c|c|c|c|}
\hline Factor studied & & New Foci & Distance & Area & Perimeter & Angle \\
\hline \multicolumn{7}{|c|}{ Initial patch size $\left(\mathrm{m}^{2}\right)$} \\
\hline \multirow[t]{3}{*}{2008} & 1 & 0 & - & - & - & - \\
\hline & 10 & 0 & - & - & - & - \\
\hline & 100 & 0 & - & - & - & - \\
\hline \multirow[t]{3}{*}{2009} & 1 & 2 & $13.0(3.7)$ & $<0.1(<0.1)$ & $0.7(0.2)$ & $<0.1(<0.1)$ \\
\hline & 10 & 3 & $37.2(7.5)$ & $0.4(0.6)$ & $2.1(2.4)$ & $-1.3(2.3)$ \\
\hline & 100 & 7 & $41.8(12.9)$ & $8.1(7.6)$ & $12.3(9.3)$ & $0.6(5.6)$ \\
\hline \multirow[t]{3}{*}{2010} & 1 & 2 & $35.6(10.7)$ & $5.9(8.1)$ & $9.3(10.8)$ & $-1.5(2.1)$ \\
\hline & 10 & 2 & $49.8(12.9)$ & $22.0(2.6)$ & $24.2(2.3)$ & $3.5(2.1)$ \\
\hline & 100 & 3 & $55.0(8.3)$ & $10.4(2.3)$ & $15.7(1.2)$ & $-0.7(2.1)$ \\
\hline
\end{tabular}

Initial plant density (shoots $\mathrm{m}^{-2}$ )

$\begin{array}{llllllll}2008 & 4 & 0 & - & - & - & - \\ & 20 & & & & - & - & \\ & 100 & 1 & 54.1(-) & 10.1(-) & 13.8(-) & -3.0(-) \\ 2009 & 4 & 6 & 40.5(14.8) & 1.4(3.3) & 2.93(5.2) & 1.2(2.5)\end{array}$


$\begin{array}{lllll}3 & 38.2(10.1) & 0.0(0.0) & 0.08(0.0) & -3.3(1.2)\end{array}$

100

$6 \quad 40.0(19.5) \quad 12.7(15.3) \quad 15.5(15.3) \quad-0.2(0.8)$

2010

4

$4 \quad 48.4(10.7) \quad 15.7(15.7) \quad 16.6(12.1) \quad-0.3(1.5)$

20

$2 \quad 40.4(41.3) \quad 71.7(28.9) \quad 38.5(22.2) \quad<0.1(<0.1)$

100

$1 \quad 56.8(-) \quad 5.2(-)$

$21.2(-) \quad-1.0(-)$ 


\section{Figure caption}

Fig. 1. a) Sorghum halepense patch growth as a function of its initial size. Black quadrats of different sizes $\left(1,10\right.$ and $\left.100 \mathrm{~m}^{2}\right)$ are the initial patches in 2007 and dotted areas correspond to patch location in every year. b) Soghum halepense patch growth as a function of initial plant density. Quadrats with different colors (light gray: 4 plants $\mathrm{m}^{-2}$; gray: 20 plants $\mathrm{m}^{-2}$; and black: 100 plants $\mathrm{m}^{-2}$ ) represent the initial patches in 2007 and dotted areas correspond to patch location in every year. Arrows show the tillage direction.

Fig. 2. Growth of Sorghum halepense patches in four successive years started from six individual plants. Arrows show the tillage direction.

Fig. 3. Plant density evolution in four successive years for: a) patches with the same initial density (20 plants $\mathrm{m}^{-2}$ ) and different initial patch sizes; and b) patches with the same initial size $\left(10 \mathrm{~m}^{2}\right)$ and different initial plant densities.

Fig. 4. Average complexity index (ratio area perimeter $^{-2}$ ) evolution in four successive years for: a) patches with the same initial density $\left(20\right.$ plants $\left.\mathrm{m}^{-2}\right)$ and different initial patch size; and b) patches with the same initial size $\left(10 \mathrm{~m}^{2}\right)$ and different initial plant densities.

Fig. 5. Average anisotropy (ratio between the projection in the direction of traffic and the projection in the direction perpendicular to traffic) evolution in four successive years for: a) patches with the same initial density $\left(20\right.$ plants $\left.\mathrm{m}^{-2}\right)$ and different initial patch size; and b) patches with the same initial size $\left(10 \mathrm{~m}^{2}\right)$ and different initial plant densities. 
Fig. 6. Average increase in the density of $S$. halepense (shoots $\mathrm{m}^{-2}$ ) during the first and second year after planting a single rhizome piece at each site. 


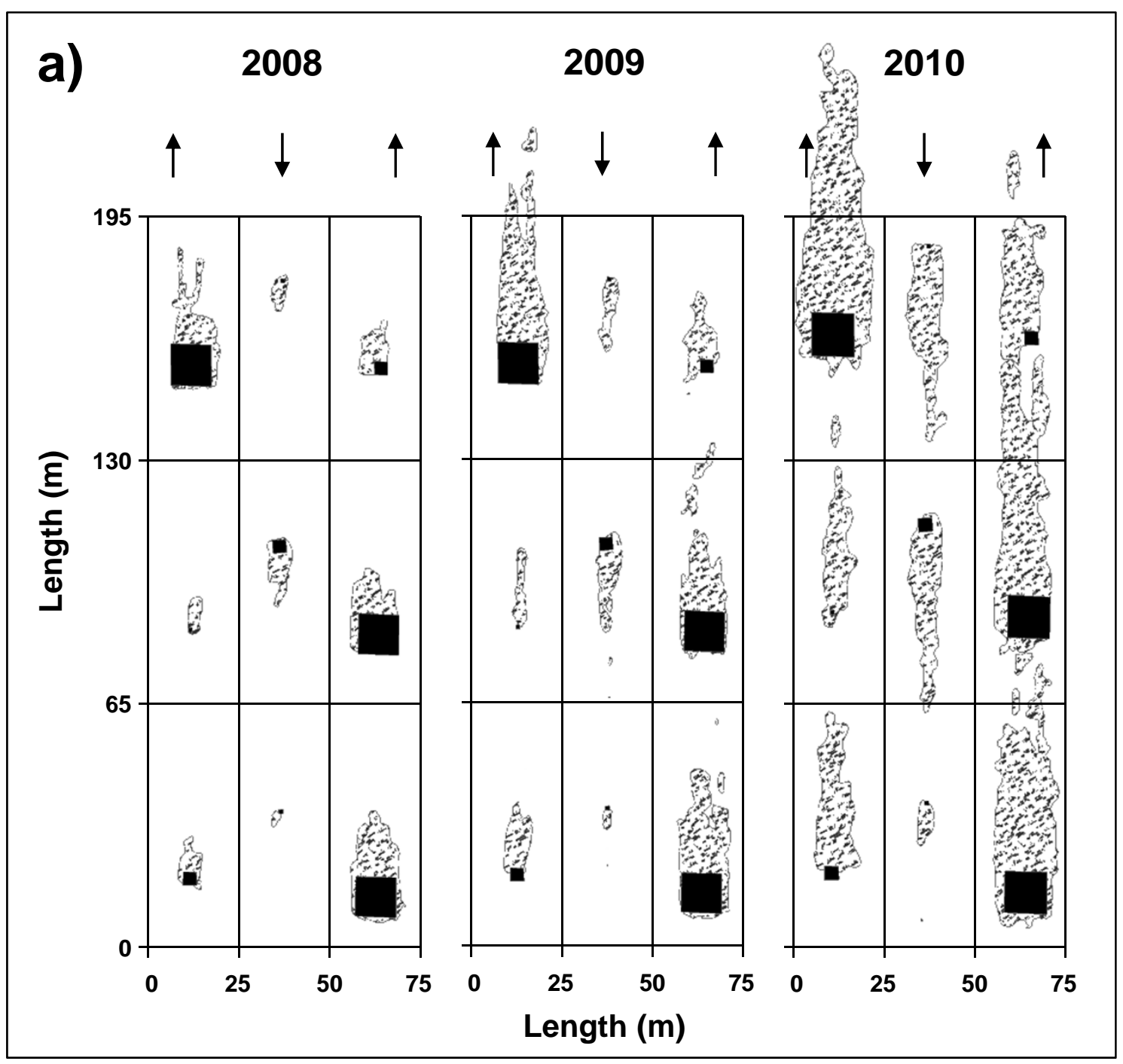

Fig. 1

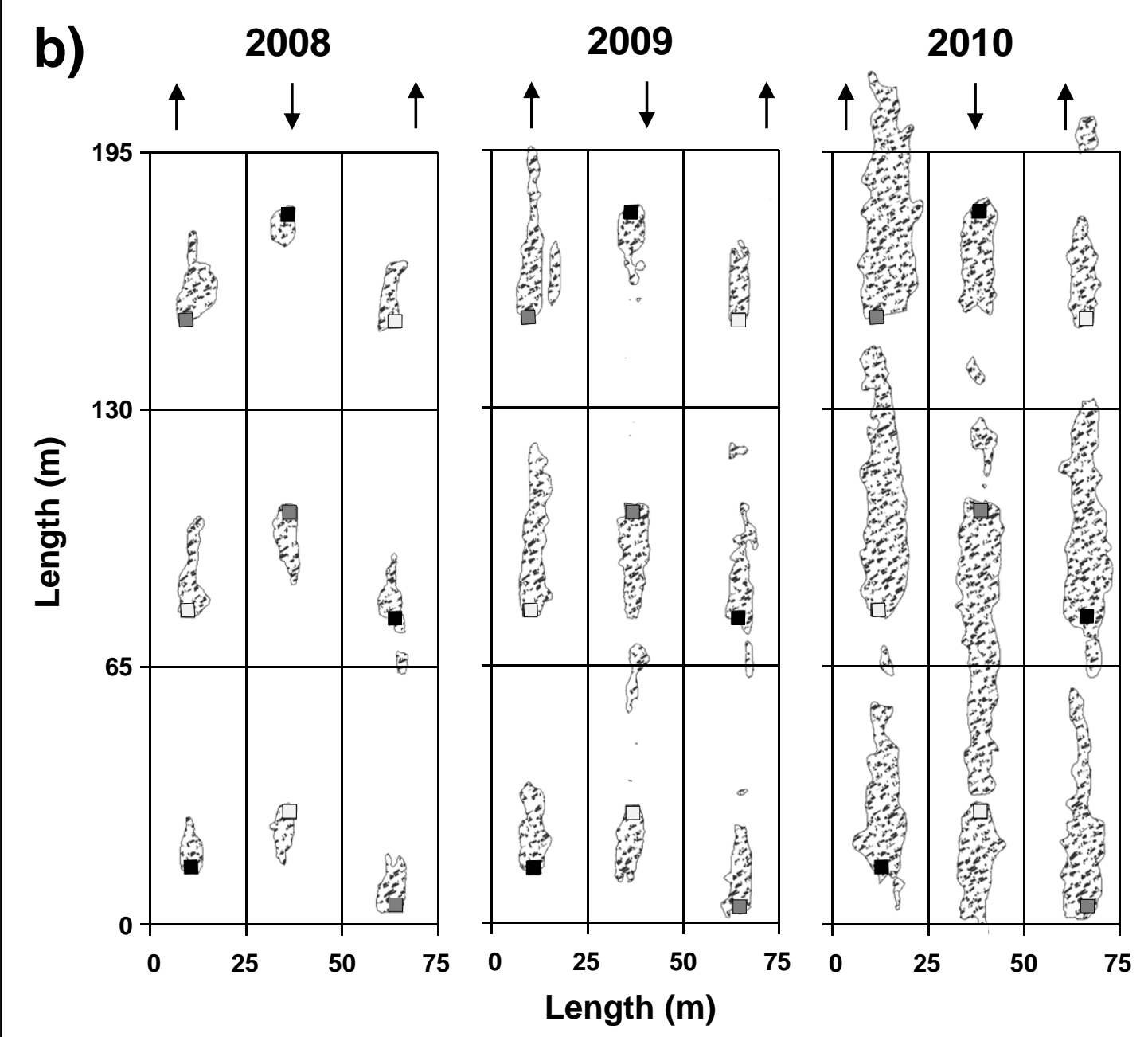




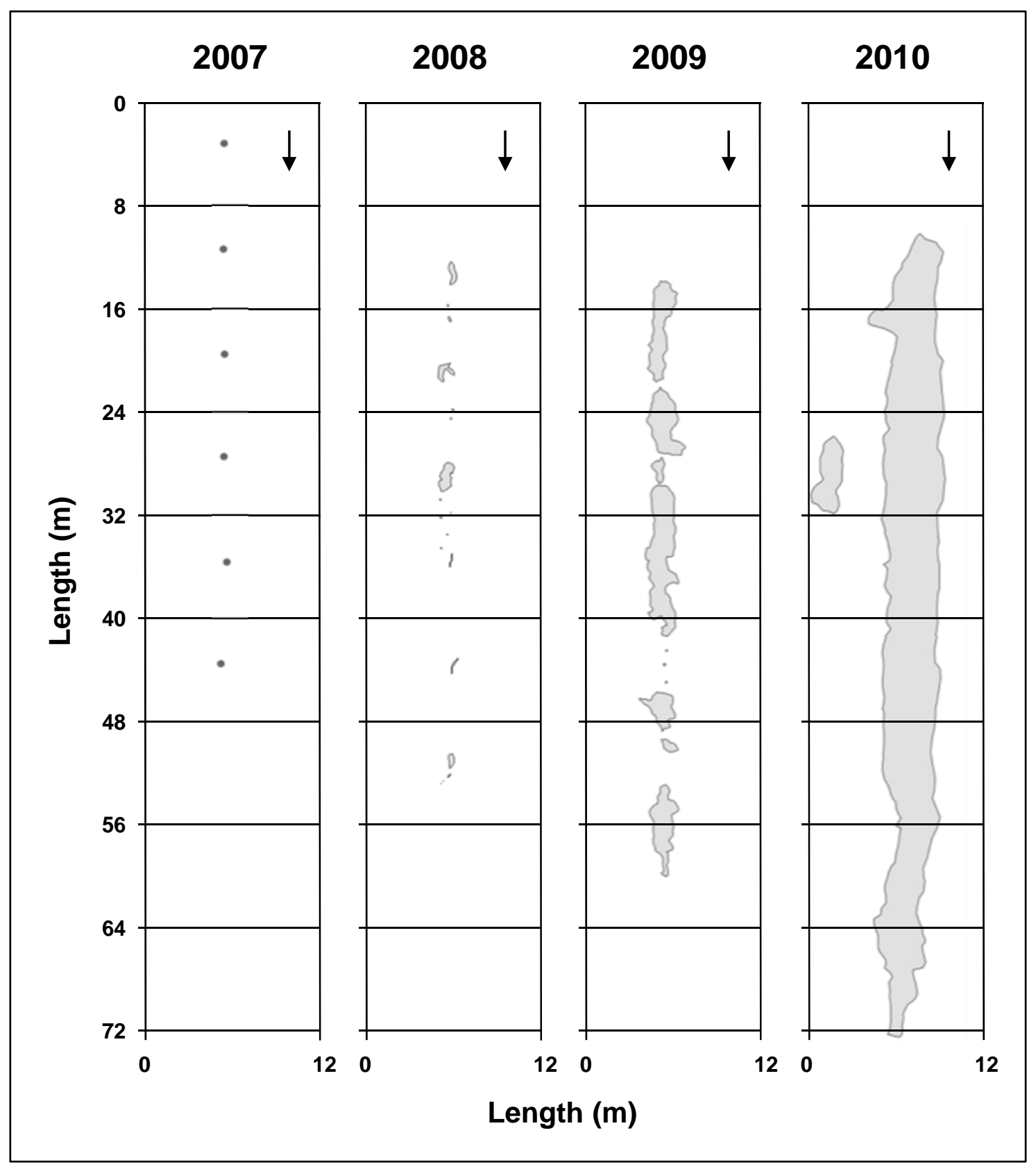

Fig. 2 

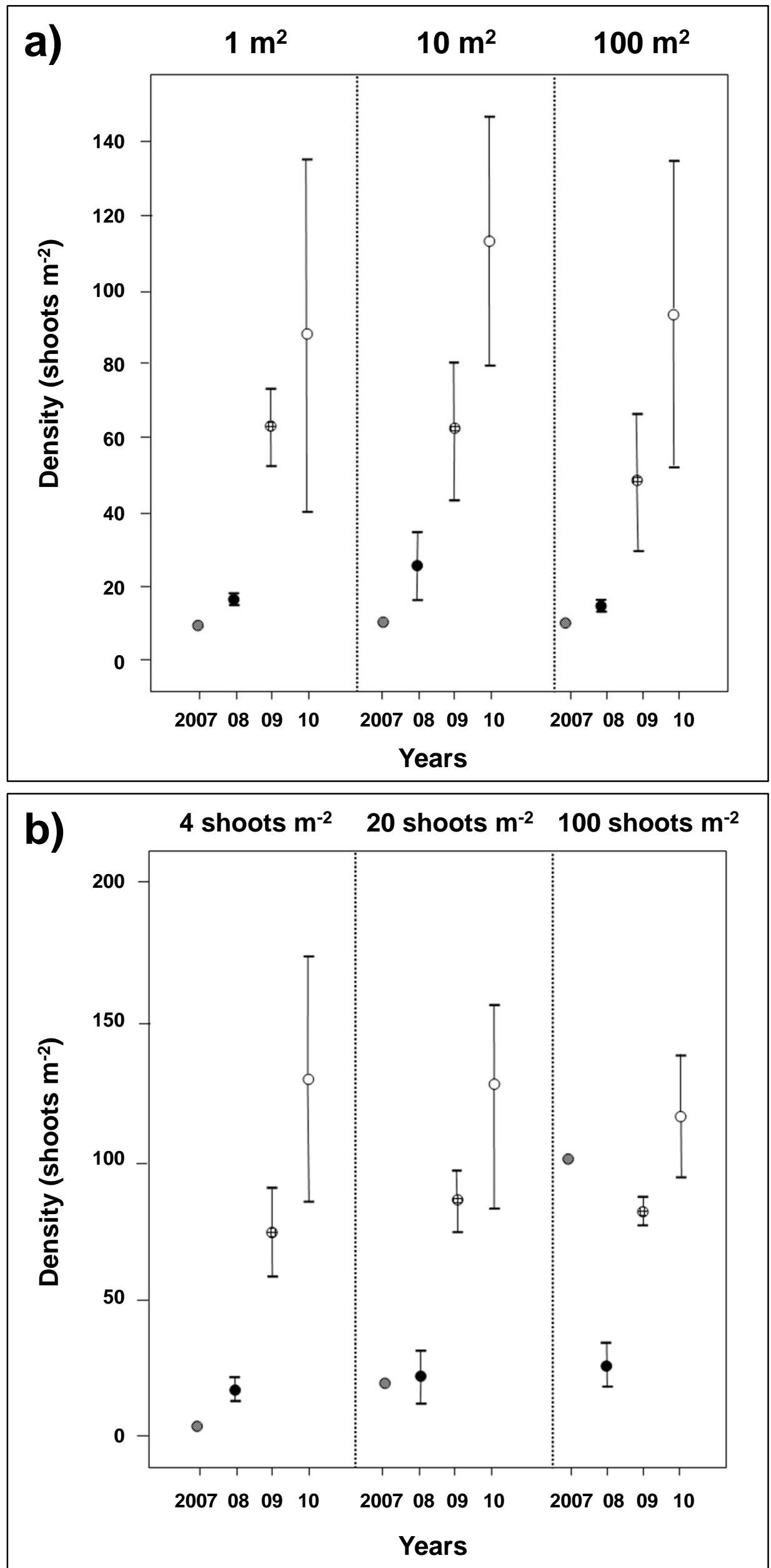

Fig. 3 

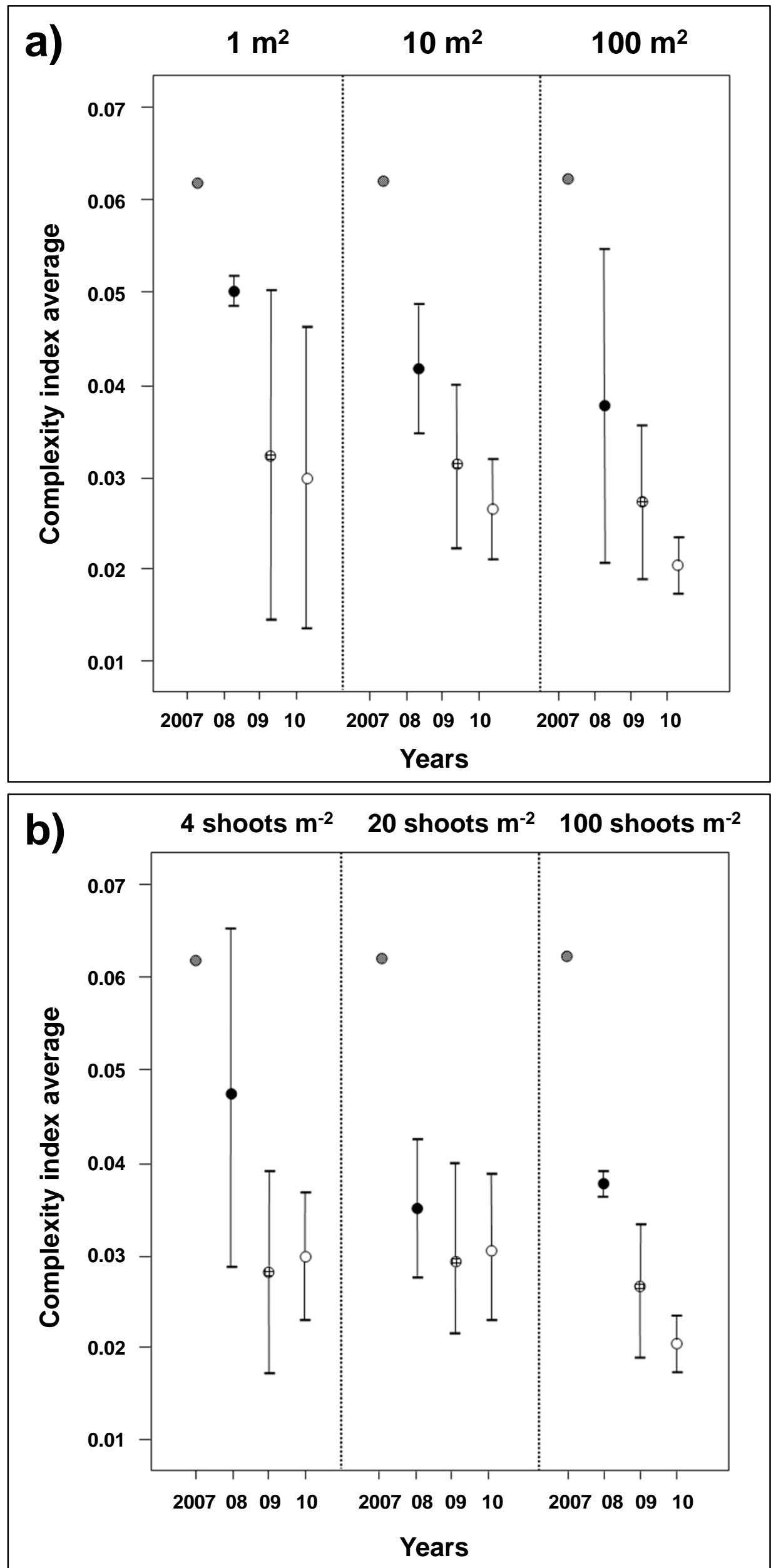

Fig. 4 

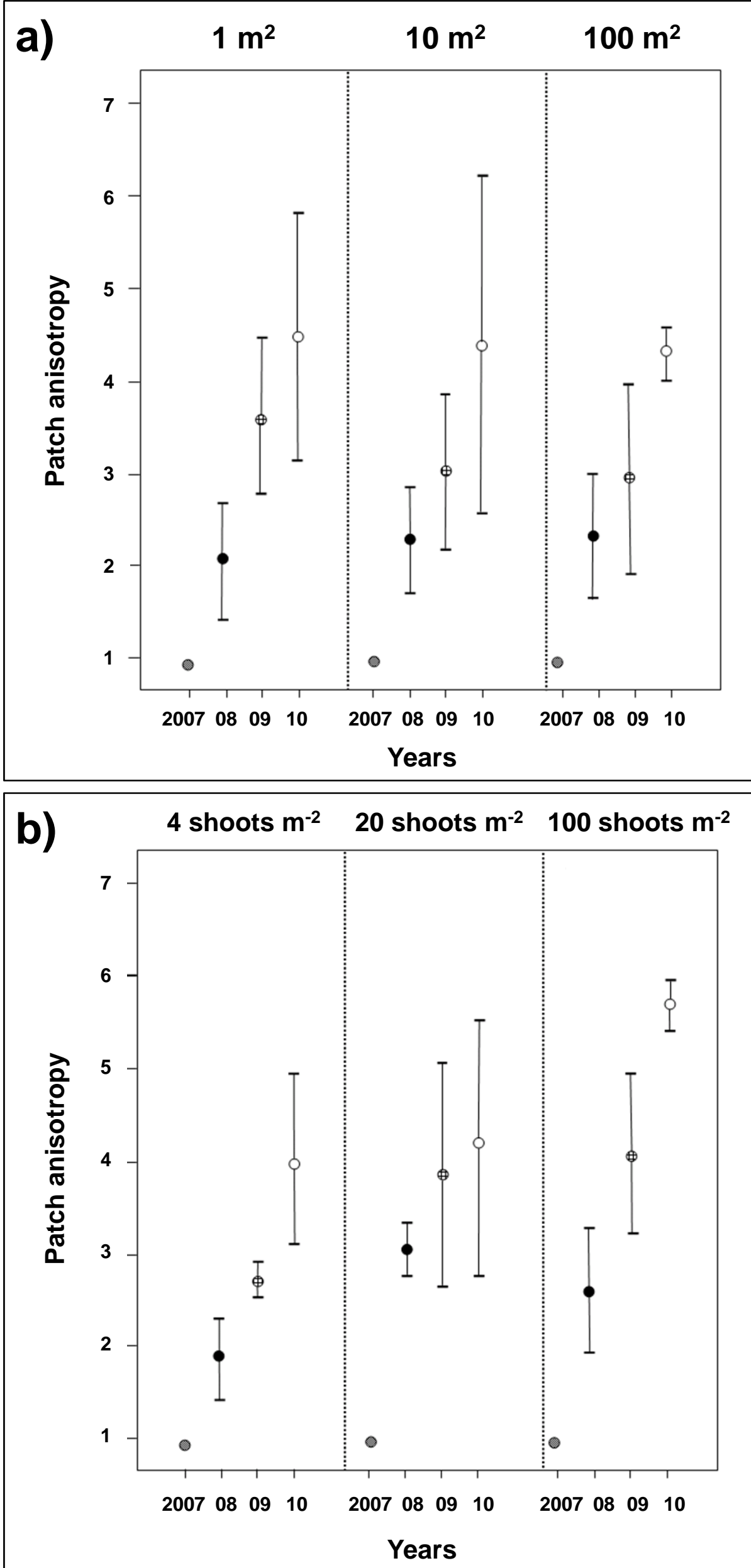

Fig. 5 


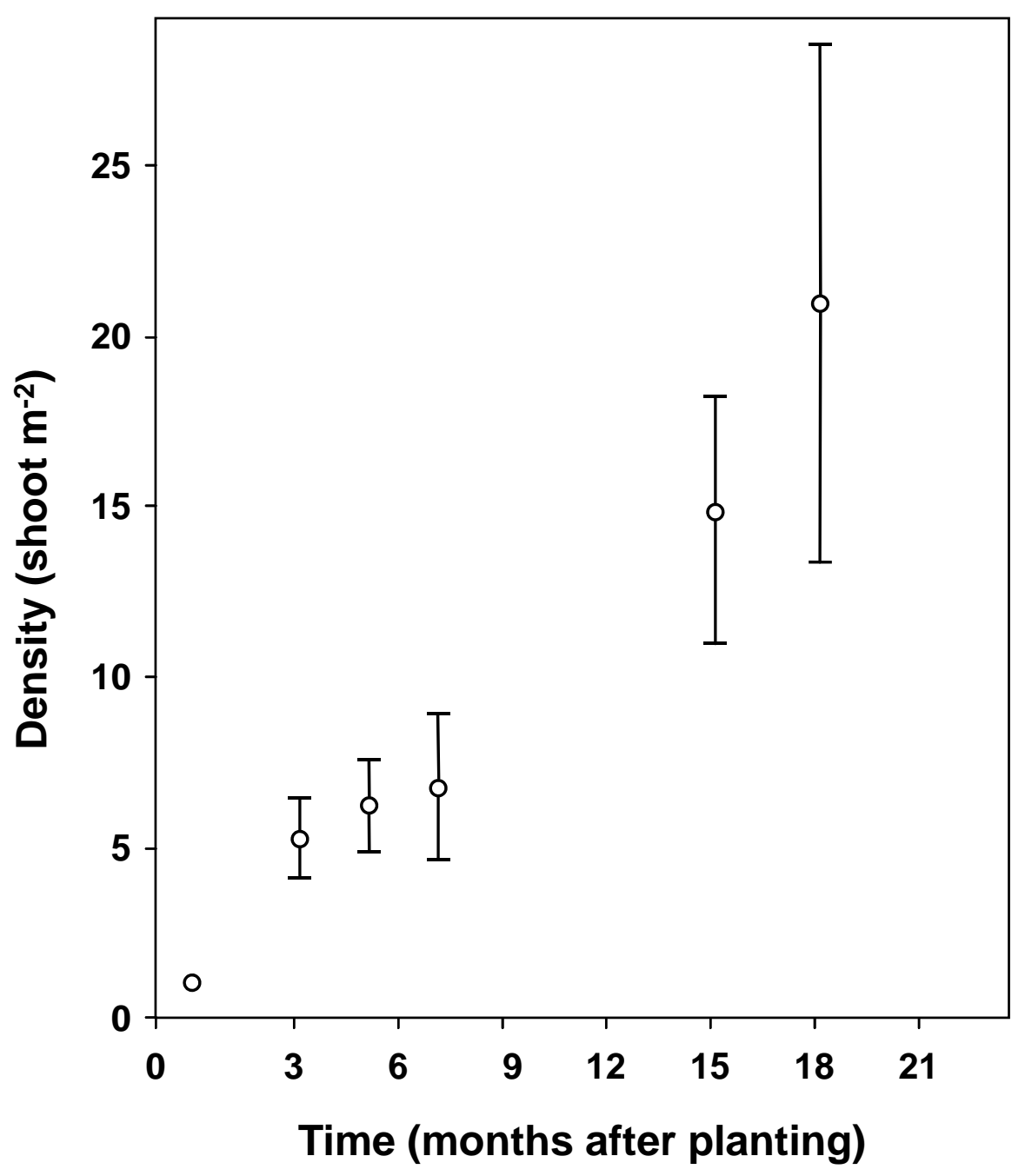

Fig. 6 